\title{
Experimental determination and study of horizontal forces during rolling
}

\author{
Vladlen Mazur ${ }^{1}$, Viktor Artiukh ${ }^{2, *}$ and Yuriy Sagirov ${ }^{3}$ and Sergey Kuznezov ${ }^{4}$ \\ ${ }^{1}$ LLC «Saint-Petersburg Electrotechnical Company», Pushkin, Parkovaya, 56, Saint-Petersburg, \\ 196603, Russia \\ ${ }^{2}$ Peter the Great St.Petersburg Polytechnic University, Polytechnicheskaya, 29, St. Petersburg, \\ 195251, Russia \\ ${ }^{3}$ Pryazovskyi State Technical University, Universytets'ka, 7, Mariupol, 87500, Ukraine \\ ${ }^{4}$ South Ural State University (National Research University), Nizhnevartovsk Branch, Mira str., 9, \\ 628600 , Russia
}

\begin{abstract}
Results of experimental and theoretical studies of horizontal accelerations of rolls, chocks and housings of strip/sheet rolling stands are shown. Relations between horizontal forces and dynamic rolling torques, sequence of their arise are described. Significant influence of gaps in system 'chock - housing' and radial gaps in main drive lines on values of work rolls chocks horizontal impacts against housings is proved. Influence of rolled metal dimensions, mass and speed of rolled metal before metal-in on dynamic forces of work rolls chocks horizontal impacts against housings is described by means of developed mathematical relation.
\end{abstract}

\section{Introduction}

Practice of studies of dynamic loads arising inside rolling equipment usually consists of several stages:

- determination of inertia forces arising due to changes of speeds and accelerations of moved masses (equipment details);

- $\quad$ study of relations between different dynamic loads and sequence of their arise;

- determination of influence of gaps between contact surfaces and gaps closure time on dynamic loads values;

- $\quad$ study of influence of rolled metal dimensions, masses and speeds of technological performance on dynamic loads values.

In modern dynamic loads research practices a lot of attention is paid to horizontal forces during rolling (which horizontally move rolls chocks with further impacts of rolls chocks against housings). Necessary stages of horizontal forces study are:

- $\quad$ determination of inertia forces during metal bite by work rolls (WRs);

- $\quad$ study of horizontal accelerations of WRs chocks and housings;

* Corresponding author: artiukh@mail.ru 
- determination of relations between horizontal forces and dynamic rolling torques (in main drive lines) and sequence of their arise;

- $\quad$ study of influence of gaps in system 'chock - housing' and main drive line on horizontal forces values;

- $\quad$ study of influence of rolled metal dimensions, masses and speeds of metal bite by WRs on dynamic loads values.

\section{Formulation of task}

Experimental studies of WRs chocks and housings accelerations were not widely popular several decades ago due to necessity to use expensive laboratory equipment. Hence, direct measurement (by contact sensors) of forces of WRs chocks horizontal impacts against housings and control of chocks movements in housings windows were done. In addition, it was necessary to make slots in rolling stands details for such contact sensors that could weaken equipment.

In modern experimental practices measurements of details accelerations have become widespread due to:

- $\quad$ significant costs reduction of laboratory equipment;

- installation of sensors is done on details prepared surfaces without necessity to machine equipment.

Furthermore, analysis of accelerations during unsteady and steady rolling helps to scrutinize dynamics of rolling equipment during rolling.

\section{Objectives of this paper:}

- $\quad$ analysis of experimental results on horizontal forces and studies of rolling stands details movements;

- consideration of theoretical methods calculations of rolling stands details horizontal impacts against reciprocal elements taking into account their horizontal oscillations;

- display of forces calculations results of WRs chocks horizontal impacts against housings depending on rolling technology, masses of rolled metal and technical conditions of rolling stand.

\section{Materials and Methods}

Necessity to make damping of horizontal oscillations of WRs and horizontal forces during rolling with increased reductions and high rolling speeds for production of high strength and ultrafine grained types of steel is shown in [1]. Objectives to reduce dynamic horizontal forces are improve of quality and structure of steel thing strip and increase of rolling stand durability. Horizontal accelerations of housings details where WRs chocks hit them when stabilizer installed in rolling stand of Pohang Iron and Steel Company (Gwangyang city, South Korea) was turned on and turned off are shown on fig. 1. Due to turned-off stabilizer there were accelerations equal to around $3 \mathrm{~g}$, when the stabilizer was turned-on there were accelerations equal to around $1 \mathrm{~g} \div 2 \mathrm{~g}$. The stabilizers is a hydraulic cylinder installed in slot of housing (two stabilizers are used) on entry side (ES) which constantly presses WR chock to delivery side (DS) of housing that results in elimination of gap between WR chock and housing. Use of the stabilizer reduces horizontal force of WR chock impacts against housings by $50 \%$.

Frequency of bottom WR (BWR) horizontal oscillations in described rolling stand was around $60 \div 90 \mathrm{~Hz}$. 


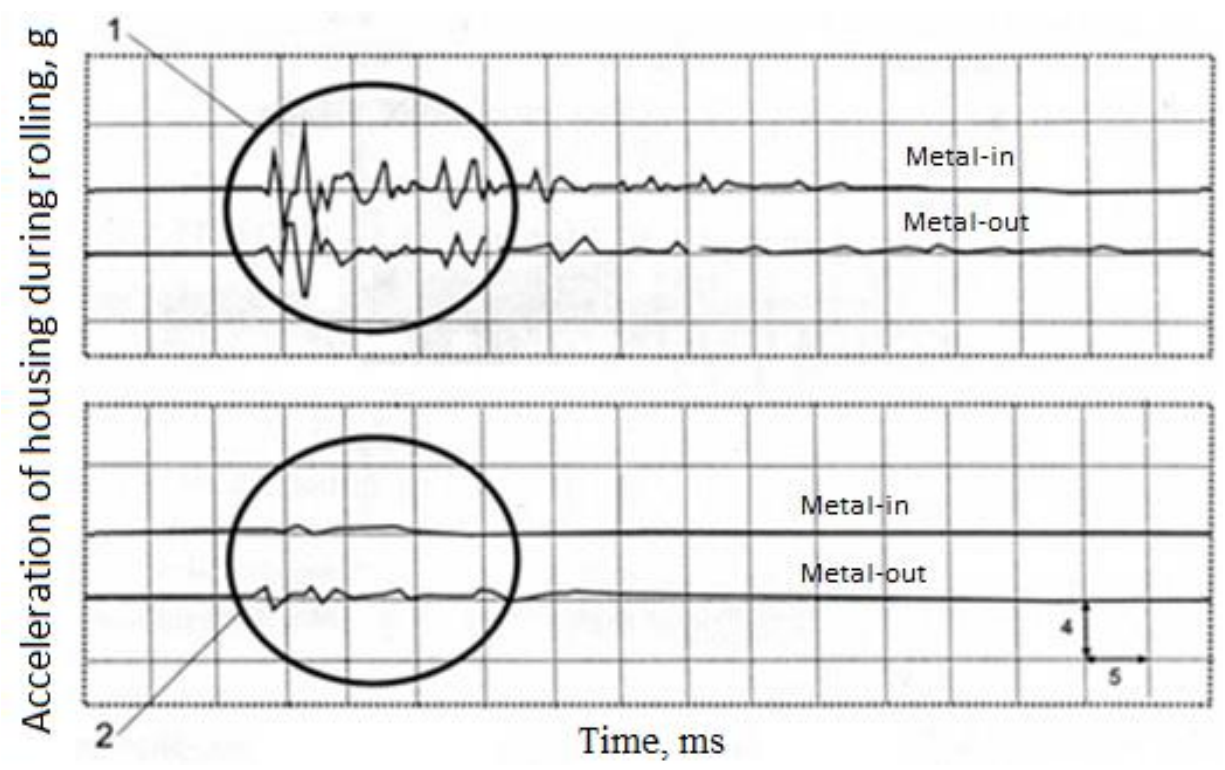

Fig. 1. Accelerations of housing on ES during rolling: 1 - the stabilizer is turned-off; 2 - the stabilizer is turned-on

There is experimental data on accelerations and movements of WRs chocks of reversing roughing 4-hi thick sheet rolling stand of PJSC 'Illich Iron and Steel Works of Mariupol' (Ukraine) [2] and reversing finishing 4-hi thick sheet rolling stand of PJSC 'Azovsteel Iron and Steel Works' (Ukraine) [3]. Acceleration sensors were installed on BWR chocks on drive side (DS) and operator side (OS). Movement sensors of BWR chocks were installed on housings and these sensors contact elements were installed on BWR chocks. Experimentally obtained accelerations and movements of BWR chocks during rolling are shown on fig. 2 [2].

According to fig. 2 maximum accelerations are $-82 \mathrm{~m} / \mathrm{s}^{2}$ on OS during the third pass and $-81 \mathrm{~m} / \mathrm{s}^{2}$ on DS during the first pass. Sign minus means that movements of BWR chocks were towards ES. In addition, there are numerous accelerations from $25 \mathrm{~m} / \mathrm{s}^{2}$ to $65 \mathrm{~m} / \mathrm{s}^{2}$. When gap $\delta$ (refer to fig. 4) increases from $1.0 \mathrm{~mm}$ to $3.5 \mathrm{~mm}$ it results in accelerations increase by $50 \%$.

Moreover, movements of BWR with chocks in windows of housings were defined (below given sequence of movements corresponds to $90 \%$ cases of steady rolling):

a. WR chock is in the middle of housing window or pressed to any column of housing before rolling;

b. WR chock moves against rolling direction during metal-in (start of rolling, unsteady rolling), hits column of housing and then there are numerous fading impacts of WR chock against columns of housing on ES and DS;

c. WR chock is pressed to housing on ES during steady rolling;

d. WR chock hits column of housing on ES during metal-out. 

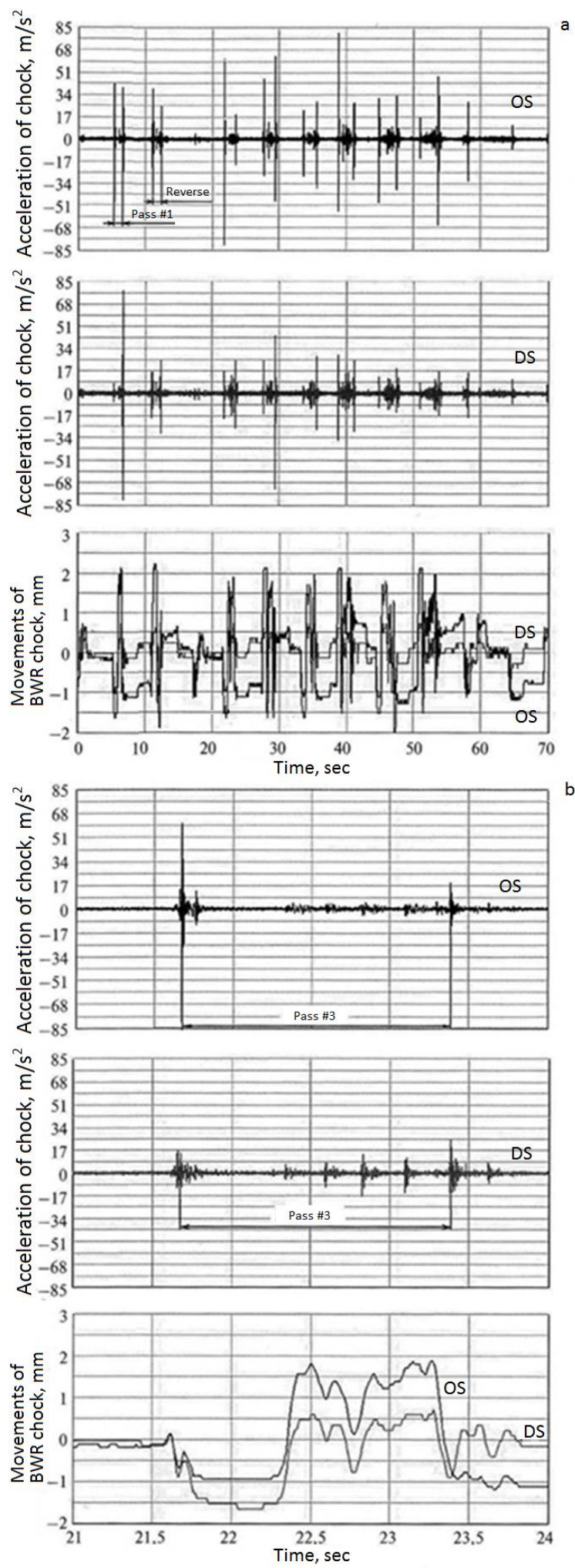

Fig. 2. Oscillogram of slab rolling (a) and part of this oscillogram (b, pass \#3) 
Small amount of works are devoted to research of relations between horizontal forces and dynamic rolling torques in main drive lines of WRs. For example, within contact zone of WR and back-up roll (BUR) horizontal forces arise [4] (refer to fig. 3) which are responsible for impacts of WRs chocks against housings.

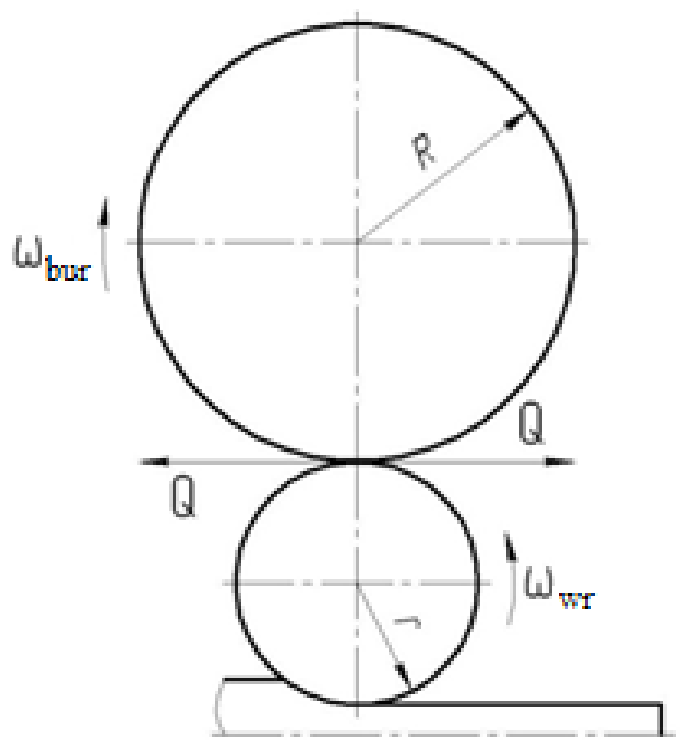

Fig. 3. Scheme for horizontal forces definition

Horizontal forces Q:

$$
Q=\frac{T_{D R}-T_{R}}{r\left[1+\left(\frac{r}{R}\right)^{2}\right]},
$$

where $\mathrm{T}_{\mathrm{DR}}$ is dynamic rolling torque acting on WR;

$\mathrm{T}_{\mathrm{R}}$ is rolling torque on WR at steady rolling;

$\mathrm{R}$ is radius of BUR being in contact with WR;

$r$ is radius of $W R$.

When $\mathrm{T}_{\mathrm{DR}}>\mathrm{T}_{\mathrm{R}}$ horizontal forces $\mathrm{Q}$ try to move WR towards rolling direction, when $\mathrm{T}_{\mathrm{DR}}<\mathrm{T}_{\mathrm{R}}$ it is vice versa.

Detailed researches of relations between horizontal forces and dynamic rolling torques in main drive lines of WRs are shown in [5]. Experimental studies results of dynamic horizontal forces and rolling force acting in roughing rolling stand of hot strip mill (HSM) 1700 [5] show that start of horizontal forces increase is earlier by $0.01 \mathrm{sec}$ than increase of rolling force. In addition, on practice for numerous roughing rolling stands of HSMs 1700 start of horizontal forces increase is earlier by $0.03 \mathrm{sec}$ than increase of dynamic rolling torques acting on spindles near WRs.

Experimental studies of influence of gap $\delta$ (refer to fig. 4 where pos. 1 is ' $i$ ' WR, pos. 2 is chock, pos. 3 is lining strap, pos. 4 is facing strip and pos. 5 is housing) between WR chock (lining strap) and housing (facing strip) on values of horizontal impacts of WRs chocks against housings $F_{\text {hor.i }}$ were done by different scientific and technical institutions. 


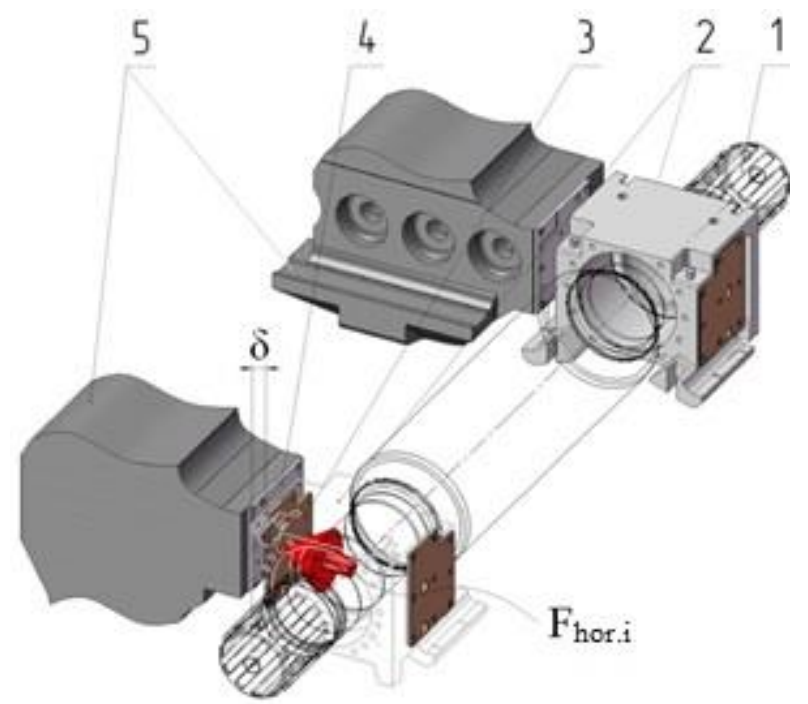

Fig. 4. Gap in system 'chock - housing'

Experimental study of accelerations of changing rails fixed to housings (on ES and DS) and gap $\delta$ on $F_{\text {hor.i }}$ acting in 6-hi rolling stand of six rolling stands strip mill of KAWASAKI STEEL (Japan) is shown in [8].

Experimental study [8] results contributed to develop an equation of rolls chocks horizontal impacts forces against housings:

$$
P_{t}=F+\sqrt{2 \cdot K_{h} \cdot F \cdot \delta}
$$

where $\mathrm{F}$ is initial horizontal force acting on roll;

$\mathrm{K}_{\mathrm{h}}$ is transverse stiffness of housing.

The resultant force of roll chock horizontal impacts against housing reduces by $60 \% \div 80 \%$ when gap $\delta$ is decreased to $0 \mathrm{~mm}$.

Determination of influence of gaps in main drive lines on roll chock horizontal impacts against housing, as usual, was done theoretically and experimentally with good results of received data matching. There is redial gap e in main drive line at start of metal-in [7], hence during some period of time $t_{\mathrm{e}}$ metal bite occurs due to kinetic energy accumulated by WRs and BURs during idle work. When time of metal bite $t$ is equal to $t_{e}$ radial gaps in top and bottom spindles become closed that results in increase of dynamic rolling torques on each spindle.

Upper value of horizontal force Q (refer to fig. 3):

$$
Q=\frac{T_{R}}{\lambda \cdot t \cdot r\left[1+\left(\frac{r}{R}\right)^{2}\right]} \cdot\left[1+\sqrt{1+\frac{\left(\lambda \cdot t_{e}\right)^{4}}{4}}\right],
$$

where $\lambda$ is frequency of main drive line torsional vibration.

Equation (3) shows that:

- $\quad$ changes of horizontal forces Q have oscillatory nature with frequency equal to frequency of main drive line torsional vibration; 
- $\quad$ values of Q depend on technological loads, design parameters of rolling stand, its details technical conditions (gaps between contact surfaces) and time of metal bite (reduction of $t$ and increase of e result in increase of Q).

According to research [10] and method of $F_{\text {hor.i }}$ calculation considering gap e (designed by authors of this paper) [11] for main drive line of roughing rolling stand \#1 of HSM 1700 of PJSC 'Illich Iron and Steel Works of Mariupol' during rolling of $8400 \mathrm{~kg}$ billet made from ferrous steel:

- $\quad$ when $\mathrm{e}=1.1 \mathrm{~mm} \mathrm{~F}_{\text {hor.i }}=1.6 \cdot 10^{6} \mathrm{~N}$

- $\quad$ when $\mathrm{e}=2.2 \mathrm{~mm} \mathrm{~F}_{\text {hor. }}=2.18 \cdot 10^{6} \mathrm{~N}$

- $\quad$ when $\mathrm{e}=3.3 \mathrm{~mm} \mathrm{~F}_{\text {hor. }}=2.76 \cdot 10^{6} \mathrm{~N}$.

Geometrical parameters of rolled metal (length, width and height), its mass and speed of metal bite have influence on dynamic loads and productivity of rolling equipment. Geometrical parameters of rolled metal define technology of rolling e.g. angle of bite, normal and frictional forces, length of deformation zone, etc. With increasing metal height and width dynamic loads can to be increased. For example, analysis of numerous oscillograms of experimental simultaneous study of $\mathrm{T}_{\mathrm{DR}}$ and $\mathrm{T}_{\mathrm{R}}$ acting on WRs/spindles and AC/DC motor shafts shows that during bigger reductions dynamics coefficients of main drive lines and $\mathrm{T}_{\mathrm{DR}}$ are smaller, although $T_{R}$ at bigger reductions are higher than $T_{R}$ at smaller ones [15-17]. Analogically, dynamics coefficients are increased by $10 \% \div 20 \%$ when rolling metal width is increased by 1.5 times [18]. It confirms that at equal terms of overhaul maintenance of particular rolling mill that consists of:

- $\quad$ roughing and finishing strip rolling stands groups, roughing stands have bigger wear compared to finishing ones;

- roughing and finishing sheet rolling stands, roughing stands have bigger wear compared to finishing ones [13].

On the basis of theoretical methods [11] applied to 4-hi reversing sheet rolling stand (Baoshan Iron \& Steel Co., Ltd; People's Republic of China; rolling force is up to 8000tons, mass of rolled metal is up to 60tons, speed of rolling $\mathrm{V}_{\text {rolling }}$ is up to $9.6 \mathrm{~m} / \mathrm{sec}$, minimum thickness of rolled sheet is till $2.4 \mathrm{~mm}$ ) influence of mismatches of $V_{\text {met }}$ (speed of metal before metal-in) and $\mathrm{V}_{\text {rolling }}$ on dynamics is shown below.

It is theoretically proved that the most acceptable mismatch of $\mathrm{V}_{\text {met }}$ and $\mathrm{V}_{\text {rolling }}$ is $\mathrm{V}_{\text {met }}=0.95 \cdot \mathrm{V}_{\text {rolling. }}$ Graph of relation during metal bite between $F_{\text {hor. BWR }}$ (force of BWR chock horizontal impact against housing) and $V_{\text {met }}$ within $[3.2 \mathrm{~m} / \mathrm{sec} ; 4.0 \mathrm{~m} / \mathrm{sec}]$ when $\mathrm{V}_{\text {rolling }}=2 \mathrm{~m} / \mathrm{sec}$ is shown on fig. 8 where mass of rolled sheet from steel API X80 $\mathrm{m}=47140 \mathrm{~kg}$, gap $\delta=0.0036 \mathrm{~m}$. It results in dynamic metal bite and impact of metal against WRs during it [12].

Graph of relation during metal bite between $F_{\text {hor. BwR }}$ and $V_{\text {met }}$ within $[1.7 \mathrm{~m} / \mathrm{sec} ; 1.9$ $\mathrm{m} / \mathrm{sec}]$ when $\mathrm{V}_{\text {rolling }}=2 \mathrm{~m} / \mathrm{sec}$ is shown on fig. 6 where $\mathrm{m}=47140 \mathrm{~kg}$, gap $\delta=0.0036 \mathrm{~m}$. It results in normal metal bite and no impact of metal against WRs during it [12]. 


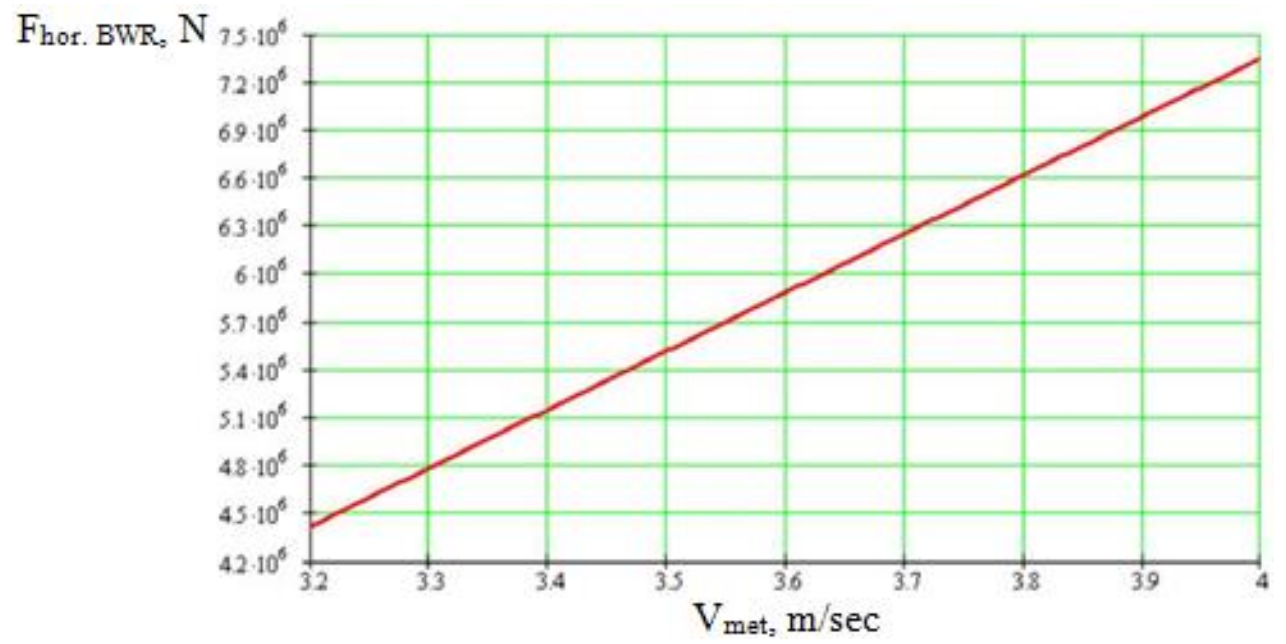

Fig. 5. Graph of relation between force of BWR chock horizontal impact against housing and speed of metal before metal-in during dynamic metal bite at rolling stand of Baoshan Iron \& Steel Co., Ltd

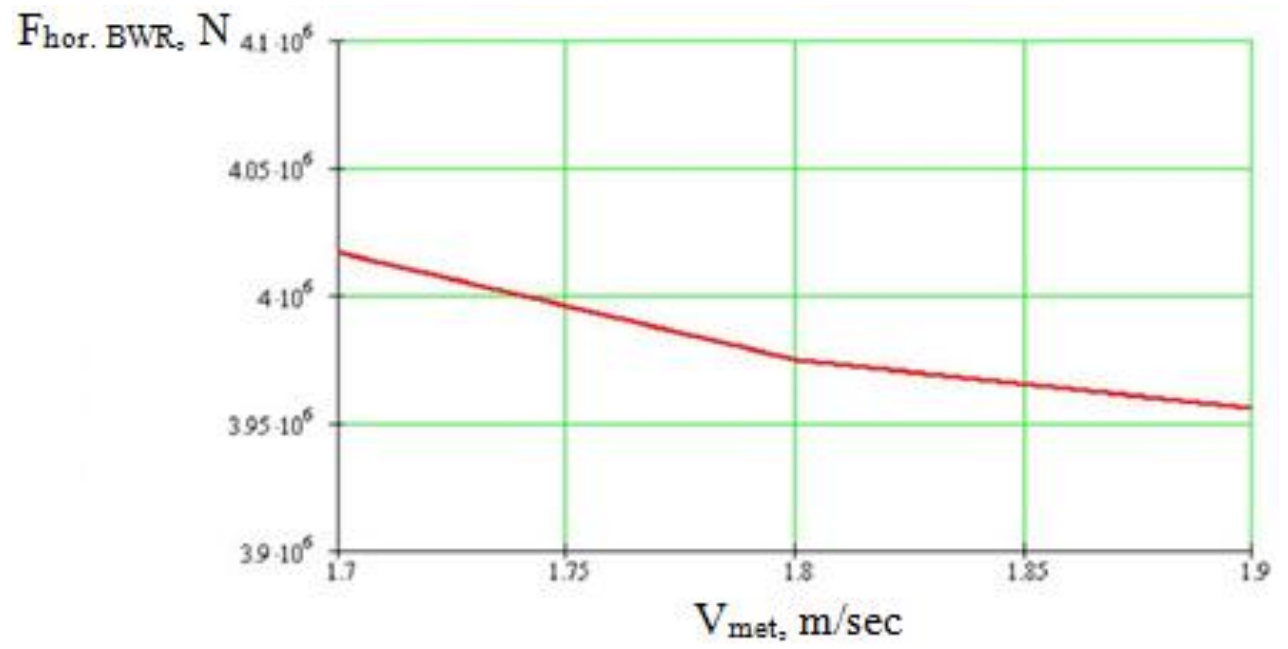

Fig. 6. Graph of relation between force of BWR chock horizontal impact against housing and speed of metal before metal-in during normal metal bite at rolling stand of Baoshan Iron \& Steel Co., Ltd

Considering data shown on fig. 5 and fig. 6 it is necessary to define mathematical relation between $F_{\text {hor.i }}$ and $V_{\text {met }}$ when there is no slippage between rolled metal and WRs during metal bite. It helps operating personnel to make preliminary theoretical calculations of $F_{\text {hor.i }}$ (assuming that WRs are loaded equally) that may result in avoidance of premature wear of details contact surfaces of 4-hi rolling stands.

Defined relation of $\mathrm{F}_{\text {hor. }}$ and $\mathrm{V}_{\text {met }}$ within $[1.7 \mathrm{~m} / \mathrm{sec} ; 4.0 \mathrm{~m} / \mathrm{sec}]$ :

$$
F_{\text {hor. } \mathrm{i}}=0.5 \cdot V_{m e t}^{3}-3 \cdot V_{m e t}^{2}+6 \cdot V_{m e t}, \mathrm{MN}
$$

Graph of equation (4) is shown on fig. 7. 


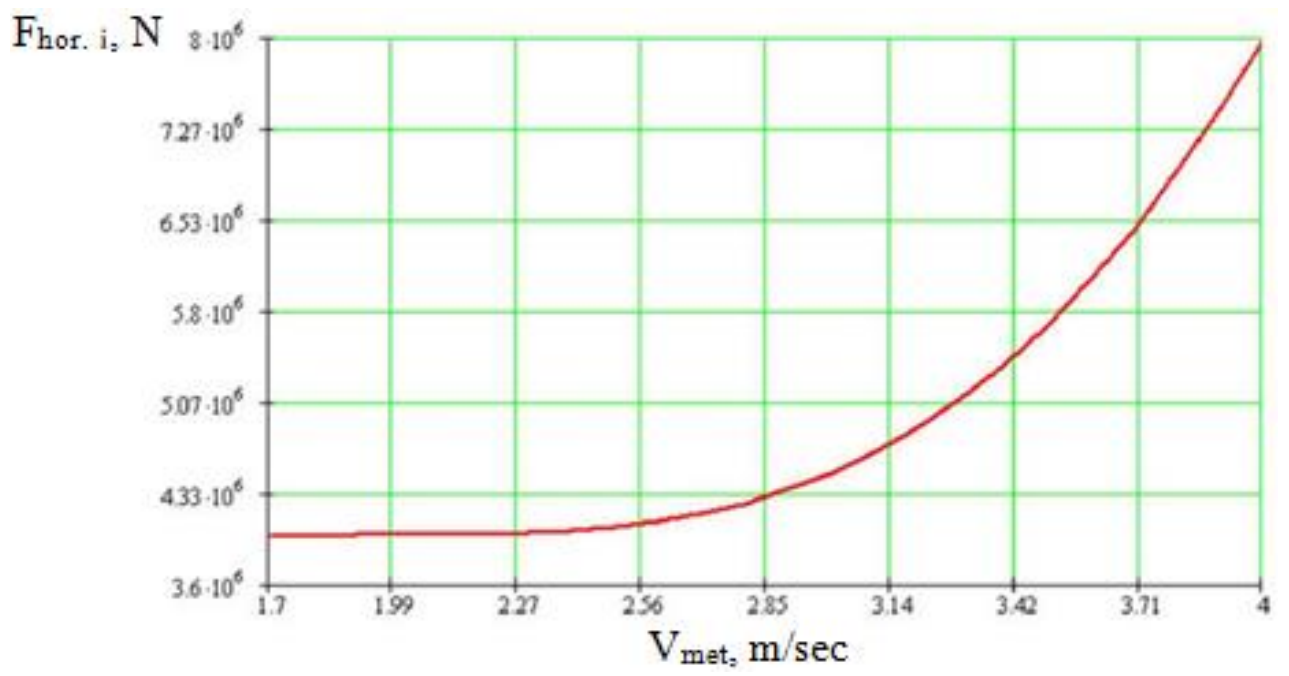

Fig. 7. Graph of relation between force of WR chock horizontal impact against housing and speed of metal before metal-in during metal bite at rolling stand of Baoshan Iron \& Steel Co., Ltd according to relation (4), gap $\delta=0.0036 \mathrm{~m}$

Its usage is possible for other strip/sheet 4-hi rolling stands when mass of rolled metal is around 45 ton $\div 48$ ton, it is made from steel API X60 $\div \mathrm{X} 80, \mathrm{~V}_{\text {rolling }}=1.8 \mathrm{~m} / \mathrm{sec} \div 2.1 \mathrm{~m} / \mathrm{sec}$ and $\mathrm{V}_{\text {met }}=1.5 \mathrm{~m} / \mathrm{sec} \div 4.2 \mathrm{~m} / \mathrm{sec}$.

Another parameter that affects technology of rolling is mass of rolled metal. Mostly, it is strictly regulated and can be reduced in exceptional cases on requiring repair equipment. Graph of relation between force of WR chock horizontal impact against housing and mass of metal during metal bite at rolling stand of Baoshan Iron \& Steel Co., Ltd is shown on fig. 8.

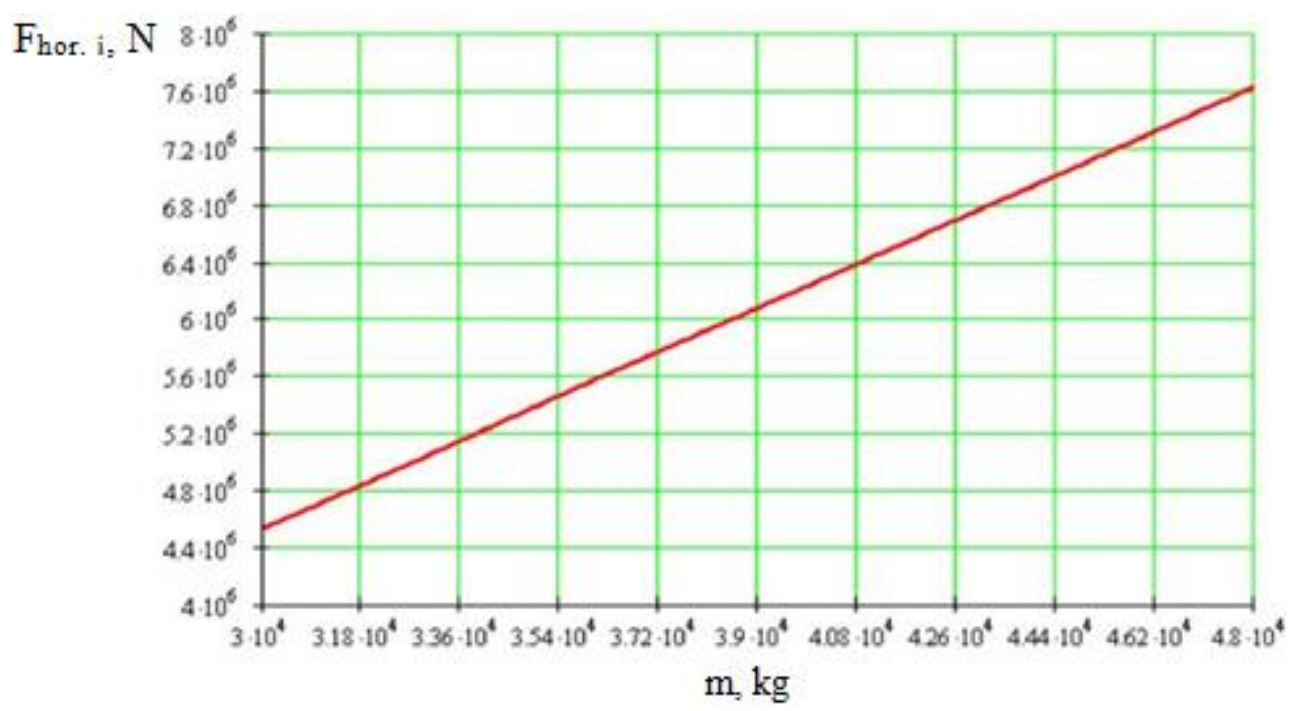

Fig. 8. Graph of relation between force of WR chock horizontal impact against housing and mass of metal during metal bite at rolling stand of Baoshan Iron \& Steel Co., Ltd, gap $\delta=0.0036 \mathrm{~m}$ 


\section{Results}

Calculations of theoretical relations (refer to fig. 8-11) are done on mathematical models (MMs) developed by authors of this paper. Calculations core of MMs is based on fundamental principles of rolling process kinematics [20], and optimal algorithm of horizontal forces calculation during unsteady and steady rolling. MMs take into account metal bite conditions (dynamic/normal), its dimensions, steel grade, mass and temperature, reduction, $\mathrm{V}_{\text {rolling }}$ and $\mathrm{V}_{\text {met, }}$, design of rolling stand, etc.

MMs were tested on the basis of experimental studies shown and analyzed in [3 and 19]. This makes it possible to successfully carry out similar calculations for other strip and sheet rolling stands.

\section{Conclusions}

1. Results of experimental and theoretical studies of horizontal accelerations of rolls, chocks and housings are shown. Horizontal accelerations of some details can be from $1 \mathrm{~g}$ till $10 \mathrm{~g}$ and they can significantly differ on OS and DS.

2. Relations between horizontal forces and dynamic rolling torques, sequence of their arise are described. Shown data proves primary action of horizontal inertial force on WRs (with further fading horizontal impacts of their chocks against housings) compared to arise and increase of dynamic rolling torque acting on spindles near WRs.

3. Significant influence of gaps in system 'chock - housing' and radial gaps in main drive lines on values of WRs chocks horizontal impacts against housings is proved. Necessity to reduce gaps to minimum values is given.

4. Technical conditions of rolling stands details have to comply with recommended wear values of contact surfaces which are set by their manufacturer and practice of operating of equipment. Exceeding these values leads to premature failure and accidental breakdowns of rolling equipment.

5. Influence of rolled metal dimensions, mass and $\mathrm{V}_{\text {met }}$ on dynamic forces of WRs chocks horizontal impacts against housings is described. Developed mathematical relation can be used on strip/sheet rolling stands, e.g. during metal bite on 4-hi rolling stand of Baoshan Iron $\&$ Steel Co., Ltd when $\mathrm{V}_{\text {rolling }}=2 \mathrm{~m} / \mathrm{sec}$ and $\delta=0.0036 \mathrm{~m}$ reduction of $\mathrm{V}_{\text {met }}$ by $20 \%$ from $4.0 \mathrm{~m} / \mathrm{sec}$ to $3.2 \mathrm{~m} / \mathrm{sec}$ theoretically can reduce $\mathrm{F}_{\text {hor. }}$ by $40 \%$ from $7.35 \mathrm{MN}$ to $4.44 \mathrm{MN}$.

6. According to any experimental results it is necessary to develop MMs to simplify process of technological and dynamic calculation by technological and operational personnel of rolling mills.

7. To reduce dynamic impacts forces of rolling equipment parts and obtain gapless connections between WR chock (lining strap) and housing (facing strip) it is possible to use technical solutions [6,9 and 14].

\section{References}

1. T. Usugi, K. Hayasi K. Ferrous metallurgy - bulletin of OJSC 'Chermetinformation', 6, 52-55 (2005)

2. A. Ishenko etc. Study of dynamic loads acting on housings of rolling mill 3000 during rolling and development of solutions to optimize work of rolling mill. Report of scientific work (Mariupol: Priazovskiy State Technical University (PSTU), 2006)

3. A. Ishenko, etc. Steel, 5, 56-58 (2009) 
4. V. Verenyov, etc. Dynamic processes in stands of wide strip mill 1680 (Dnepropetrovsk, IMA-press, 2011)

5. V. Artiukh, V. Mazur, A. Adamtsevich. MATEC Web of Conferences, 106, 04001 (2017) DOI: https://doi.org/10.1051/matecconf/201710604001.

6. V. Mazur, V. Artyukh, G. Artyukh, M. Takadzhi. Engineering Designer, 37, 26-29 (2012)

7. V. Verenyov etc. Diagnostics and dynamics of rolling mills. (Dnepropetrovsk: IMApress, 2007)

8. Y. Konno et.al. Kawassaki Giho, 33, 37-42 (2001)

9. N. S. Gharaibeh, et.al. Engineering and Technology, 8(12), 1461-1464 (2016).

10. V. Artiukh, V. Mazur, E. Pokrovskaya. MATEC Web of Conferences, 86, 01030. DOI: http://dx.doi.org/10.1051/matecconf/20168601030 (2016)

11. V. Mazur, V. Artiukh, M.I. Matarneh. Procedia Engineering, 165, 1722-1730. DOI: 10.1016/j.proeng.2016.11.915 (2016)

12. M. Zaykov etc. Rolling process (Moscow, MISIS, 2004)

13. A. Ishenko A.A., etc. Steel, 5, 63-65 (2003)

14. V. Artiukh, V. Mazur, L. Shilova. MATEC Web of Conferences, 106, 03002. DOI: https://doi.org/10.1051/matecconf/201710603002 (2017)

15. Saykin V.A., etc. Metallurgy and mining industry, 4,. 28-31 (1997).

16. V.V. Verenyov, etc. Metallurgy and mining industry, 4, pp. 64-66 (1998)

17. V.V. Verenyov, etc. Study of dynamic loads in main drive lines of roughing stands of continuous wide-strip mill 1700 and development of technical solutions for reduction of their levels for implementation of resources-saving technology of transit rolling (Dnepropetrovsk, 2006)

18. A. Molchanov, Metallurgy and mining industry, 4, pp. 36-39 (2002)

19. V. Artiukh, V. Mazur, R. Prakash. Solid State Phenomena, 871, 3-8, 2016. DOI: http://10.4028/scientific.net/MSF.871.3 (2016)

20. E. Sorochan, V. Artiukh, B. Melnikov, T. Raimberdiyev. MATEC Web of Conferences, 73, 04009. DOI: http://dx.doi.org/10.1051/matecconf/20167304009 (2016) 